\title{
FORMULATION AND DEVELOPMENT OF IN SITU FORMING GEL FOR THE TREATMENT OF ORAL THRUSH
}

\author{
AKSHAY KUMAR S, VISHAL GUPTA N, GOWDA DV*, PRAVEEN SIVADASU
}

Department of Pharmaceutics, JSS College of Pharmacy, Sri Shivarathreeshwara Nagara, Mysuru, JSS Academy of Higher Education and Research, JSS Medical Institutions Campus, Sri Shivarathreeshwara Nagara, Mysuru - 570015, Karnataka, India. Email: dvgowda@jssuni.edu.in

Received: 24 March 2018, Revised and Accepted: 05 May 2018

ABSTRACT

Objective: The objective of the present work was to develop an in situ gel composed of Pluronic F-127, Carbopol 934, and methylparaben and loaded with fluconazole using DoE software to sustain the delivery of drug in the buccal cavity.

Methods: In situ gels were prepared by temperature-induced method, by employing DoE and characterized by Fourier transform infrared (FTIR), differential scanning calorimeter (DSC), and evaluated for gelation temperature, gelation time, adhesive force, and in vitro diffusion studies.

Results: Both FTIR and DSC studies suggested that there were no chemical interactions present between both drug and polymers. The formulated gels S1, S3, and S9 showed gelation at a body temperature. The viscosity, gel strength, and mucoadhesive force for the formulated in situ gels were found to be within the ranges of 375-738 cps, 35-62 s, and 4650-5210.32 dynes/ $\mathrm{cm}^{2}$, respectively. The in vitro diffusion studies indicated that optimized in situ gel S3 exhibited the improved ability to sustain the drug compared to other formulations.

Conclusion: Thus, developed in situ gel system was determined to be effective in terms of eradication of oral thrush

Keywords: In situ gel, Pluronic F-127, Carbopol 980, Fluconazole, Oral thrush.

(C) 2018 The Authors. Published by Innovare Academic Sciences Pvt Ltd. This is an open access article under the CC BY license (http://creativecommons. org/licenses/by/4. 0/) DOI: http://dx.doi.org/10.22159/ajpcr.2018.v11i8.26190

\section{INTRODUCTION}

Oral thrush is defined as a yeast or fungal infection caused by Candida albicans, generally observed in oral cavities of babies and elderly people with dentures [1]. These fungal organisms are present in oral cavity within a wide range of population; changes in the environment of oral cavity lead to these fungal infections, other factors that trigger these fungal infections are hyposalivation, usage of immune suppressants, and radiation therapy to cure diseases [2]. To treat these fungal infections, conventional formulations such as gels, torches, creams, mouth paints, rinses, and suspensions are used to deliver the drug locally into the oral cavity. These formulations are also used to treat various conditions such as bacterial infections, fungal infections, periodontal disease, toothache, and dental caries [3].

Degradation of drugs in the oral cavity salivary fluid causes incomplete eradication of candidiasis. The delivery of drugs locally in the oral cavity will result in improved efficacy to eliminate the infection. The antifungal drugs with enhanced stability and more residence time will permit to penetrate through the tissue membrane of buccal cavity to act on Candida species for extended period [4,5]. To deliver the drug locally in the buccal cavity in this research work, in situ gel was selected as vehicle to deliver the drug due to its various advantages such as reduced dose frequency, and enhanced patient comfort and compliance $[6,7]$.

Fluconazole is a wide-spectrum antifungal drug belonging to the class of imidazole derivatives. Fluconazole shows its action by bonding with lanosterol 14-alpha-dimethylase and inhibits the production of ergosterol, in turn, leading to loss of integrity in the fungal cell membrane. In addition to this, it also decreases the binding of fungal cells to the host tissue and prohibits the multiplication and growth of fungi [8].
The main interest of the current study is to formulate thermoreversible in situ gels using Carbopol-934 and Pluronic F-127, for release of Fluconazole to treat candidiasis in the oral cavity. Hence, the systemic side effects can be reduced, improve the therapeutic efficacy and patient acceptance.

\section{MATERIALS AND METHODS}

\section{Materials}

Fluconazole was obtained as a gift sample from Bayer Pharmaceutical Pvt., Ltd, Thane, India, and Pluronic F-127was obtained as a gift sample from Triveni Interchem Pvt., Ltd, Vapi, India.

\section{Methods}

Formulation and optimization of temperature-induced in situ gel loaded with fluconazole.

\section{Experimental design}

A $3^{2}$ randomized full factorial design for the study of in situ gel at two factors and three levels. Factors included in the study Pluronic F-127 and Carbapol-934 are used as independent variables, whereas levels -1 and +1 were used as low and high, respectively. Viscosity, $\mathrm{pH}$, and gelation time were used as dependent variables. Best fit model for statistical analysis was considered significant when $p$ value was $<0.05$. Design-Expert software (DX11) State-Ease Inc., USA, was used to study the effect of different variables dependent on the properties of viscosity, $\mathrm{pH}$, and gelation time [9].

Formulation of temperature-induced in situ gel loaded with fluconazole

Thermoreversible in situ gels were prepared using cold technique; this process involves slow addition of Pluronic F-127 and methylparaben in a sufficient quantity of cold distilled water. The required quantity 
of Carbopol 934 was taken in another beaker and allowed it to swell for overnight. Polymer solutions were stirred until uniform solutions were obtained using a magnetic stirrer (Remi, India). The mixture was then kept at room temperature for $24 \mathrm{~h}$. To adjust the $\mathrm{pH}$ to 7 , a little quantity of triethanolamine was added. Fluconazole was weighed and solubilized in dimethylsulfoxide by stirring continuously until a uniform drug solution was formed. Drug solution was incorporated into gel before in vitro studies [1]. The different variables and compositions of thermoreversible gels obtained from DoE were given in Tables 1 and 2 .

\section{Characterizations}

Fourier transform-infrared (FTIR) studies

The nature of drug-excipient interacting forces during gelation process was characterized using FTIR by employing potassium bromide pellet method [10].

\section{Differential scanning calorimetry}

All differential scanning calorimeter (DSC) studies of pure drug and physical mixture were done using Shimadzu DSC-TSW 60. A few $\mathrm{mg}$ of sample were entirely sealed into aluminum crimp pan cells. Under nitrogen atmosphere, it was heated at constant temperature of $10^{\circ} \mathrm{C} / \mathrm{min}[10]$.

\section{Evaluation of prepared in situ gels Visual appearance and clarity}

The formulated gels were examined for visual appearance and clarity by observing the formulated in situ gels against a white and black background to check the presence of any particulate matter [11]

$p H$

The most accurate common means of measuring $\mathrm{pH}$ are through a laboratory device called a probe $\mathrm{pH}$ meter. Measurement is made by submerging the probe in the liquid until a reading is registered by the meter $[12,13]$.

\section{Viscosity}

Viscosity of all formulated in situ gels was done using Brookfield viscometer using spindle no. 6 at $30 \mathrm{rpm}$, at two different temperatures, namely $8 \pm 1^{\circ} \mathrm{C}$ and $37 \pm 1^{\circ} \mathrm{C}[12,14]$

\section{Gelation temperature and gelation time}

Evaluation of gelation temperature and gelation time was done by taking required quantity of gelling a thin-walled test tube and places it in a thermostatically controlled water bath with frequent shaking until it got converted to gel. Complete gelation was confirmed by tilting the test tube upside down, where the gel does not flow out. The gel formation was evaluated visually and gelation time was observed $[12,15]$.

\section{Determination of mucoadhesive force}

Mucoadhesive force can be termed as strength required to disconnect the formulated gel from oral mucosa. Mucoadhesive force was determined using modified balance technique. This method was done using chicken mucosa and two vials. Tissue specimen with appropriate thickness and surface area was taken from chicken mucosa and tied to each side of vial using thread and stored at $32-34^{\circ} \mathrm{C}$ for about $15 \mathrm{~min}$. Weighing balance was attached to one of the vials and specified quantity of gel was positioned between the tissue specimens attached to bottom of the vials. The force required to detach the gel from mucosa was measured [16].

\section{In vitro diffusion studies}

The in vitro diffusion study of the formulated in situ gel was performed by modified USP dissolution apparatus-1. A Whatman filter paper was taken in the basket and wetted by dipping in simulated lacrimal fluid for a time period of at least $1 \mathrm{~min}$ to ensure the contact of release medium with formulation. $100 \mu \mathrm{l}$ of the formulation was applied to the Whatman filter paper and $50 \mathrm{ml}$ of simulated lacrimal fluid was filled in a beaker and basket was rotated over its surface. At regular intervals, $3 \mathrm{ml}$ samples were withdrawn replaced with an equal amount of fresh simulated lacrimal fluid. The samples were analyzed spectrophotometrically for fluconazole content using ultraviolet (UV)visible spectrophotometer (Shimadzu UV-1800) at $286 \mathrm{~nm}[17,18]$.

\section{RESULTS AND DISCUSSION}

\section{Characterization}

FTIR studies

The IR spectra of pure drug Fluconazole were compared with the IR spectra of physical mixture. The comparison between two spectra

Table 1: Variables in $3^{2}$ factorial design of fluconazole loaded in situ gels

\begin{tabular}{lll}
\hline Variables & Low (\%) & High (\%) \\
\hline Pluronic F-127 (X1) & 12 & 15 \\
Carbopol 934 (X2) & 0 & 0.04 \\
\hline
\end{tabular}

Table 2: $3^{2}$ factorial design layout for fluconazole loaded in situ gels

\begin{tabular}{lll}
\hline Run & $\begin{array}{l}\text { Pluronic F-127 (X1)/factor } \\
\mathbf{1}(\mathbf{m l})\end{array}$ & $\begin{array}{l}\text { Carbopol 934 (X2) factor } \\
\mathbf{2}(\mathbf{m g})\end{array}$ \\
\hline 1 & 15 & 0.02 \\
2 & 15 & 0 \\
3 & 15 & 0.04 \\
4 & 13.5 & 0 \\
5 & 13.5 & 0.04 \\
6 & 13.5 & 0.02 \\
7 & 12 & 0.02 \\
8 & 12 & 0.04 \\
9 & 12 & 0 \\
\hline
\end{tabular}

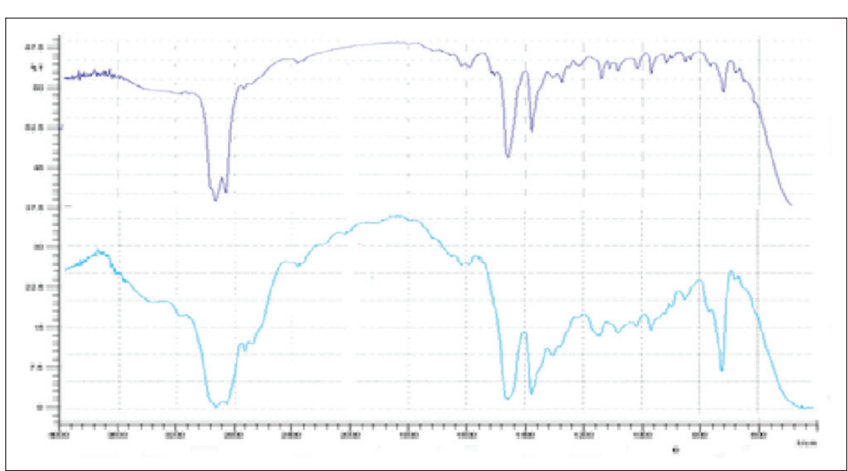

Fig. 1: Fourier transform-infrared spectra of pure drug and drugexcipient mixture

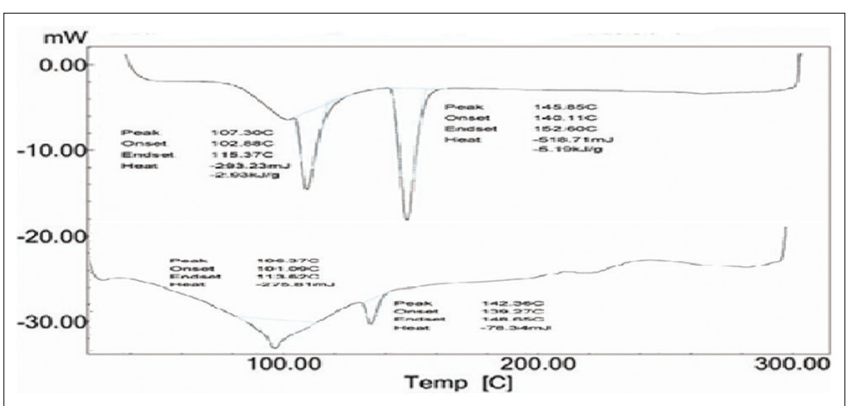

Fig. 2: Differential scanning calorimeter of pure drug and physical mixture 


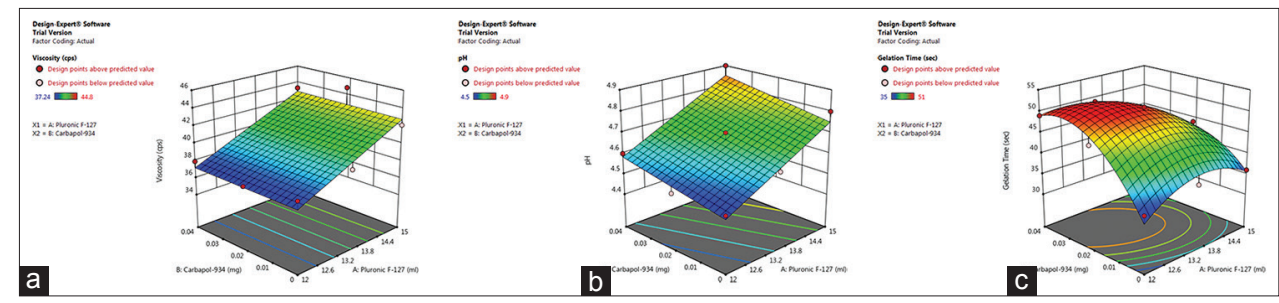

Fig. 3a-c: Three-dimensional response surface plot depicting the impact of factors over responses

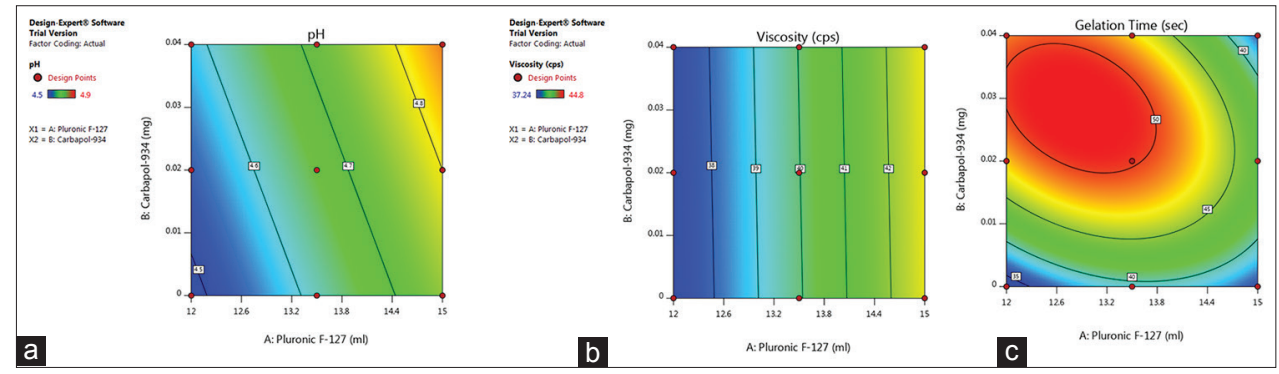

Fig. 4a-c: Contour plot showing the impact of the impact of factors over responses

Table 3: Observed response in $3^{2}$ factorial design for temperature-induced in situ gel loaded with fluconazole

\begin{tabular}{|c|c|c|c|c|c|c|}
\hline Std. & Run & $\begin{array}{l}\text { Pluronic F-127 (X1)/factor } \\
1(\mathrm{ml})\end{array}$ & $\begin{array}{l}\text { Carbapol-934 (X2) } \\
\text { Factor } 2(\mathrm{mg})\end{array}$ & $\begin{array}{l}\text { Response Y1 } \\
\text { pH }\end{array}$ & $\begin{array}{l}\text { Response Y2 } \\
\text { viscosity (cps) }\end{array}$ & $\begin{array}{l}\text { Response Y3 gelation } \\
\text { time (s) }\end{array}$ \\
\hline 6 & 1 & 15 & 0.02 & 4.7 & 44.8 & 36 \\
\hline 3 & 2 & 15 & 0 & 4.8 & 42.1 & 44 \\
\hline 9 & 3 & 15 & 0.04 & 4.9 & 43.3 & 35 \\
\hline 2 & 4 & 13.5 & 0 & 4.6 & 39.09 & 37 \\
\hline 8 & 5 & 13.5 & 0.04 & 4.7 & 38.3 & 49 \\
\hline 5 & 6 & 13.5 & 0.02 & 4.7 & 39.02 & 51 \\
\hline 7 & 8 & 12 & 0.04 & 4.6 & 37.92 & 49 \\
\hline 1 & 9 & 12 & 0 & 4.5 & 38 & 35 \\
\hline
\end{tabular}

Table 4: Results of regression analysis for responses

\begin{tabular}{llll}
\hline Responses & Value & F-value & p-value \\
\hline $\mathrm{pH}$ & & & \\
$\mathrm{R}^{2}$ & 0.8690 & 19.91 & $<0.0022$ \\
Adjusted $\mathrm{R}^{2}$ & 0.8254 & & \\
Predicted $\mathrm{R}^{2}$ & 0.7016 & & \\
Adequate precision & 11.4891 & & 0.0057 \\
Viscosity & & & \\
\multicolumn{1}{c}{$\mathrm{R}^{2}$} & 0.8211 & 13.77 & \\
Adjusted $\mathrm{R}^{2}$ & 0.7615 & & 0.0374 \\
Predicted $\mathrm{R}^{2}$ & 0.6223 & & \\
Adequate precision & 7.5647 & & \\
Gelation time & & & \\
$\quad \mathrm{R}^{2}$ & 0.9489 & 11.15 & \\
Adjusted $\mathrm{R}^{2}$ & 0.8638 & & \\
Predicted $\mathrm{R}^{2}$ & 0.3955 & & \\
Adequate precision & 8.4959 & & \\
\hline
\end{tabular}

was studied, and it was observed that there was no interaction between pure drug and drug-excipients mixture which was depicted in Fig. 1.

\section{Differential scanning calorimetry}

It was evident that DSC of physical mixture and pure drug showed endothermic peak corresponding to fluconazole around $145.85^{\circ} \mathrm{C}$ as depicted in Fig. 2. Hence, from the results, it was inferred that there was no interaction between the pure drug and physical mixture.
Formulation and optimization of temperature induced in situ gel loaded with fluconazole

From the results depicted in Table 3, it was evident that variables that have chosen have a strong impact on responses. On application of factorial design, the following regression equations were obtained. In which negative values indicate negative effect of a specific variable on the response factor and positive value indicates positive effect of a specific variable.

$\mathrm{pH}=+3.41667+0.088889$ Pluronic F-127+2.5 Carbapol-934

Viscosity $=+14.35944+1.89333$ Pluronic F-127+2.75000Carbapol-934

Gelation Time $=-363.52778+58.83333$ Pluronic

F-127+2579.16667Carbapol-934

ANOVA studies suggested that all the models were significant for the responses shown which were depicted in Table 4, and polynomial regression results were expressed using three-dimensional graphs and contour plots which were depicted in Figs. 3a-c and 4a-c.

\section{Optimization}

To design the optimized in situ gel, required response values were depicted in Table 5. The combination which resulted in achieving the required specifications was done using the design expert software. To validate the obtained model, the obtained results were overlapped with predicted results. 
Table 5: Optimization of temperature-induced in situ gel loaded with fluconazole

\begin{tabular}{llllll}
\hline Value & Pluronic F-127 (m) & Carbapol-934 (mg) & Response pH & Response viscosity (cps) & Response gelation time (s) \\
\hline Predicted & 14.932 & 0.03 & 4.9 & 43.3 & 35 \\
Actual & 14.82 & 0.03 & 4.9 & 43.1 & 36 \\
\% error & 0.112 & - & - & 0.2 & 1 \\
\hline
\end{tabular}

Table 6: Results of evaluated physiochemical parameters

\begin{tabular}{|c|c|c|c|c|c|c|c|c|c|}
\hline Tests & S1 & S2 & S3 & S4 & S5 & S6 & S7 & S8 & S9 \\
\hline Visual appearance & Clear & Clear & Clear & Clear & Clear & Clear & Clear & Clear & Clear \\
\hline $\mathrm{pH}$ & 4.7 & 4.8 & 4.9 & 4.6 & 4.7 & 4.7 & 4.5 & 4.6 & 4.5 \\
\hline Viscosity (Cps) & 44.8 & 42.1 & 43.3 & 39.09 & 38.3 & 39.02 & 37.24 & 37.92 & 38 \\
\hline
\end{tabular}

Table 7: Results of prepared formulations for gelation temperature and time

\begin{tabular}{lll}
\hline Formulation & Gelation temperature $\left({ }^{\circ} \mathbf{C}\right)$ & Gelation time $(\mathbf{s})$ \\
\hline S1 & $35 \pm 0.99$ & $36 \pm 0.97$ \\
S2 & $33 \pm 1.24$ & $44 \pm 1.02$ \\
S3 & $24 \pm 1.12$ & $35 \pm 1.15$ \\
S4 & $22 \pm 1.25$ & $37 \pm 1.23$ \\
S5 & $26 \pm 1.29$ & $49 \pm 1.56$ \\
S6 & $32 \pm 1.02$ & $51 \pm 1.58$ \\
S7 & $37 \pm 1.58$ & $46 \pm 1.63$ \\
S8 & $41 \pm 1.25$ & $49 \pm 1.35$ \\
S9 & $46 \pm 1.65$ & $35 \pm 1.53$ \\
\hline
\end{tabular}

*Mean \pm SD, n=3. SD: Standard deviation

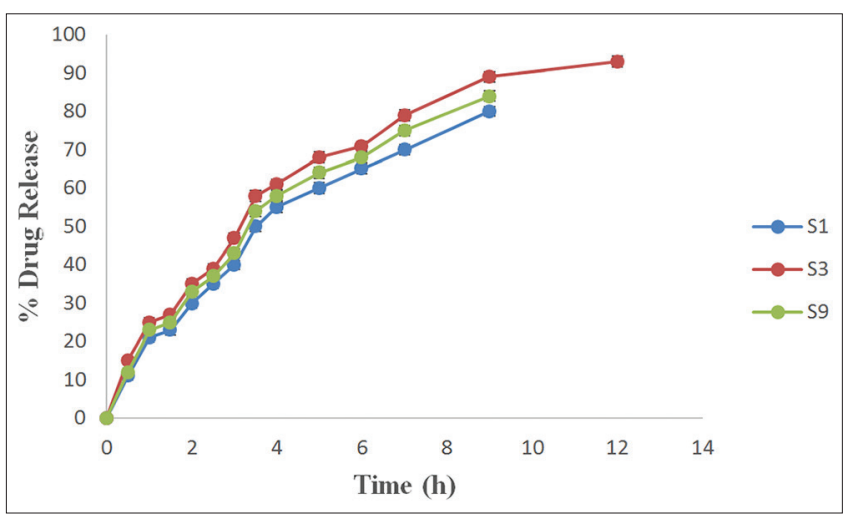

Fig. 5: In vitro diffusion profile of $S 1, S 3$, and $S 9$

\section{Evaluation of formulated in situ gels}

Clarity

The visual appearance of formulated gel (S1-S11) was found to be clear when observed against a white and black background, and the results were depicted in Table 6 .

\section{$p H$}

The optimal $\mathrm{pH}$ range for any in situ gel is $4.7-4.9$ and the formulated gels loaded with Fluconazole had shown within the range of 4.6-4.9 as depicted in Table 6. From the results obtained, it can be inferred that $\mathrm{pH}$ of the formulated in situ gels was within the range.

\section{Viscosity}

The viscosities of the formulated gels were found to be within the range of 38-45 cps which was depicted in Table 6. From the results, it can be inferred that as the concentration of Pluronic F-127 increases there was an increase in viscosity, due to decreased distance between micelles which, in turn, lead to increased interactions between them and resulting in developing viscous gels.

\section{Gelation temperature and time}

As depicted in Table 7, all the formulated in situ gels had shown gel-like viscosity within a temperature range of $22-59^{\circ} \mathrm{C}$ and the formulations showed gelation within 35-51 s depending on the concentrations of Pluronic F-127 and Carbopol-934. From the results obtained, it was inferred that S1, S3, and S9 had shown gelation at body temperature, whereas formulation S3 and S9, i.e. $35 \mathrm{~s}$ had shown gelation faster when compared with other formulations and every addition of $0.1 \% \mathrm{w} / \mathrm{w}$ $\mathrm{CP} 934$ into the formulations leaded to $5^{\circ} \mathrm{C}$ increase in gelation temperature.

\section{Mucoadhesive force}

Results obtained from mucoadhesive force study suggested that adhesive property of Pluronic F-127 increases with increase in concentration of Carbopol-934. Formulation S3 had shown more strength (5210.32 dynes $/ \mathrm{cm}^{2}$ ) when compared with $\mathrm{S} 1$ (4650.29dynes $/ \mathrm{cm}^{2}$ ) and S9 (5123dynes $/ \mathrm{cm}^{2}$ ). From the results, it can be inferred that more the mucoadhesive force, more it can prevent fallout of the gelled solution from mucosa.

\section{In vitro diffusion studies}

The formulated gels S1, S3, and S9 retarded drug release from in situ gel for $10-12 \mathrm{~h}$ as depicted in Fig. 5. Results suggested that S3 formulation has sustained the release of drug up to $12 \mathrm{~h}$, while formulations S1 and S9 had completely diffused the drug within $8 \mathrm{~h}$. From the results obtained, it can be inferred that as the concentration of polymers increased, release of drug from in situ gel was retarded.

\section{CONCLUSION}

Thermoreversible in situ gels loaded with fluconazole were formulated and optimized successfully by cold technique by employing DoE software. FTIR and DSC studies suggested that there was no chemical interaction present between the pure drug and physical mixture. Among different formulations S1, S3, and S9 have shown gelation at body temperature. From the data obtained from in vitro studies and mucoadhesive study as S3 was considered as optimum formulation as it sustained the release of the drug up to $12 \mathrm{~h}$ and shown a mucoadhesive strength of 5210.32 dynes $/ \mathrm{cm}^{2}$, while other formulations diffused the drug completely by $6-8 \mathrm{~h}$ and shown a mucoadhesive strength of 4650.29 dynes $/ \mathrm{cm}^{2}$ and 5123 dynes $/ \mathrm{cm}^{2}$. From the results, it can be concluded that formulated in situ gel can be used as an alternative approach to treat candidiasis.

\section{ACKNOWLEDGMENTS}

The authors express their gratitude to the ISS Academy of Higher Education and Research and JSS College of Pharmacy, Mysuru, for providing necessary support in due course of the work.

\section{AUTHOR'S CONTRIBUTIONS}

Author is a faculty in division of pharmaceutics and the work contributed on faculty development program in the institution. 


\section{CONFLICTS OF INTEREST}

The author confirms that this article content has no conflicts of interest.

\section{REFERENCES}

1. Harish NM, Prabhu P, Charyulu RN, Gulzar MA, Subrahmanyam EV. Formulation and evaluation of in situ gels containing clotrimazole for oral candidiasis. Indian J Pharm Sci 2009;71:421-7.

2. Chattopadhyay A, Caplan DJ, Slade GD, Shugars DC, Tien HC, Patton LL, et al. Incidence of oral candidiasis and oral hairy leukoplakia in HIV-infected adults in north Carolina. Oral Surg Oral Med Oral Pathol Oral Radiol Endod 2005;99:39-47.

3. Melo NR, Taguchi H, Culhari VP, Kamei K, Mikami Y, Smith SN, et al. Oral candidiasis of HIV-infected children undergoing sequential HIV therapies. Med Mycol 2009;47:149-56.

4. Chang JY, Oh YK, Kong HS, Kim EJ, Jang DD, Nam KT, et al. Prolonged antifungal effects of clotrimazole-containing mucoadhesive thermosensitive gels on vaginitis. J Control Release 2002;82:39-50

5. Ning MY, Guo YZ, Pan HZ, Yu HM, Gu ZW. Preparation and evaluation of proliposomes containing clotrimazole. Chem Pharm Bull 2005;53:620-4.

6. Zhidong L, Jaiwei L, Shufang N, Hui L, Pingtian D, Weisan P. Study of an alginate/HPMC based in situ gelling ophthalmic delivery system for gatifloxacin. Int J Pharm 2006;315:12-7.

7. Pandey P, Dahiya M. A brief review on inorganic nanoparticles. J Crit Rev 2016;3:18-26.

8. Ekiert RJ, Krzek J, Talik P. Chromatographic and electrophoretic techniques used in the analysis of triazole antifungal agents-a review.
Talanta 2010;82:1090-100.

9. Rao MR, Shelar SU, Yunusi A. Controlled release floating oral in situ gel of Itopride hydrochloride using $\mathrm{pH}$ sensitive polymer. Int J Pharm Pharm Sci 2014:6:338-43.

10. Patil PR, Salve VK, Thorat RU, Puranik PK, Khadabadi SS. Modern encroachment and provocation in nasal drug delivery system. Int $\mathrm{J}$ Pharm Sci Res 2013;4:2569-75.

11. Shaikh R, Shah S, Patel K, Patel B, Patel P. A review on polymers used in in-situ drug delivery systems. Int J Pharm Res Sci 2012;1:17-31.

12. Miyazaki S, Suzuki S, Kawasaki N, Endo K, Takahashi A, Attwood D. In situ gelling xyloglucan formulations for sustained release ocular delivery of pilocarpine hydrochloride. Int J Pharm 2001;229:29-36.

13. Maheswaran A, Padmavathy J, Nandhini V, Saravanan D, Angel P. Formulation and evaluation of floating oral in situ gel of diltiazem hydrochloride. Int J App Pharm 2017;9:50-3

14. Saudagar RB, Khandbahale SV. Formulation development and evaluation of nasal in-situ gel of fluticasone propionate. Int J Curr Pharm Res 2017;9:45-54.

15. Walewijk A, Cooper-White JJ, Dunstan DE. Adhesion measurements between alginate gel surfaces via texture analysis. Food Hydrocoll 2008;22:91-6

16. Deshkar SS, Patil AT, Poddar SS. Development of thermosensitive gel of fluconazole for vaginal candidiasis. Int $\mathrm{J}$ Pharm Pharm Sci 2016;8:391-8

17. Galgatte UC, Kumbhar AB, Chaudhari PD. Development of in situ gel for nasal delivery: Design, optimization, in vitro and in vivo evaluation. Drug Deliv 2014;21:62-73

18. Sanjay R, Jigar V, Vijay P, Dhaval R. A review on in-situ polymeric drug delivery system. Indian J Drug Formul Res 2011;2:143-68. 